\title{
Infantile Dream Reports in Patients with Frontal Deficits
}

\author{
Claudio Colace, M.D., Ph.D ${ }^{1 *}$, Paolo Salotti, M.D., ${ }^{2}$ Mila Ferreira, M.D. ${ }^{2}$ \\ 1 Ambulatorio di Psicologia dell'Adulto, U.O.C. Psicologia, ASL Viterbo, Italy \\ 2 Ambulatorio di Neuropsicologia dell'Adulto (Bel Colle) U.O.C. Psicologia, ASL Viterbo, Italy
}

\begin{abstract}
The neuropsychological study of dreaming, through the use of the clinical-anatomical method, is based on the observation of people who have modified their way of dreaming following a deficit in a certain area of brain. This approach has proved useful in investigating different aspects of dream processes. Some initial neuropsychological observations have suggested an infantile way of dreaming, i.e. presence of direct wish-fulfilment dreams with absence of "bizarre" elements in dream contents, in patients with frontal deficits. Infantile dreams are typically described in preschool children, and are attributed to the incomplete development of the ego and superego functions. From this perspective, the presence of infantile dreams in patients with frontal deficits has been interpreted as the result of dysfunctions of certain executive functions involved in ego and superego activities (e.g., executive tasks of the ego, adaptation to reality, self-regulation of emotional and social behaviour, inhibition) that may have determined a return to the most "primordial" mode of dreaming. This study supports these interpretations by confirming the presence of infantile dreams in a sample of 10 patients with frontal deficits through the analysis of their dream report transcriptions of the "last dream they remembered to have had". Keywords: Neuropsychology; Neuropsychoanalysis; Infantile dreams; dreaming processes; Freudian dream theory.
\end{abstract}

\section{Introduction}

The neuropsychological study of dreaming, through the use of the clinical-anatomical method, is based on the observation of people who have modified their way of dreaming, (e.g. cessation of dreaming, dreaming without visuals, increase in the frequency of dreams, etc.) following a deficit in a certain area of the brain. This approach has proved useful to some extent for the understanding of different aspects of the dream, such as dream recall (Doricchi

*Correspondence: claudio.colace@yahoo.it, +393336148977, Ambulatorio di Psicologia dell'Adulto, U.O.C. Psicologia, ASL Viterbo, Italy. Received: 23 October 2018 Accepted: 29 October 2019

\section{Sleep and Hypnosis Journal homepage: http://www.sleepandhypnosis.org ISSN:1302-1192 (Print) 2458-9101 (Online)}

\& Violani, 1992), and in particular for the study of the neuroanatomical areas that seem to be involved in the triggering of dreaming (Solms, 1997; 2000; Solms \& Turnbull, 2002; Yu, 2007).

Regarding the form and content of dreams, an early study dating back to the 5Os (Frank, 1950) and two more recent exploratory investigations (Blake, 2014; Colace, Salotti, \& Ferreira, 2015) have suggested an infantile way of dreaming, i.e. the, presence of direct wish-fulfilment dreams with absence of "bizarre" elements in dream contents ${ }^{1}$, in patients with frontal deficits (and damage to cer-

\footnotetext{
1. According to Webster's New Collegiate Dictionary, there are two features that define the word "bizarreness": 1. Improbability (strikingly out of the ordinary) and 2. Unusualness, oddness, extravagance. Many authors agree that the concept of bizarreness includes both: a) Impossibility, and b) Improbability and/or oddness compared to "common daily experiences". The first dimension includes those situations that are impossible from a physical and/or logical point of view; the second dimension implies statistical improbability (Colace, 2003). In the Freudian dream theory, most "dream bizarreness" is the expression of censorship activity in dreams, that produces distortion and disguising of latent dream contents (Freud, 1900).
} 
tain interconnected structures, e.g., the amygdala). Frank (1950) observed that patients with orbital cortex ablation showed less complex dreams, with contents of clear wish-fulfilment, like the dreams of young children. Blake (2014), recently found infantile wish-fulfilment dreams like those of young children in patients with Urbach-Wiethe syndrome, which involves congenital damage to the amygdala. Colace, Salotti, \& Ferreira (2015), found less "bizarreness" and reduced dream length (both typical of infantile dreams) in dreams of a woman suffering from a chronic degenerative disease with deficit of cerebral activity in the left dorsolateral prefrontal, operculo-insular portions of the frontal lobe, and in the right superior parietal region. This patient showed problems in executive functions, with deficits in the ability to inhibit inappropriate or irrelevant response tendencies and in the-selective or focused attention.

Freud (1901) described "infantile" or "childish" dreams in young children as short, simple (and without bizarre aspects) direct wish-fulfilment dreams instigated by unrepressed everyday wishes. Infantile dreams are typically reported by preschool children (Colace, 2010, 2013, Mari, Beretta \& Colace, 2018). The presence of these dreams is attributed to the incomplete development of the ego (less domination of thought on motivational drives) and of the superego functions (lower probability of the presence of repressed psychic material at the basis of dreams, and less dream bizarreness) (Freud, 1900, 1901). Thus, in healthy adults, unlike in young children, due the complete development of the ego, which, by virtue of the control of intentional motility, exerts a dominant and inhibitory influence on psychic drives, it becomes rare that a simple everyday wish finds fulfilment in their dreams, since adults have learned to waive such fulfilment. Moreover, in Freud's view, it is only the development of superego functions that makes it possible - and necessary-to dissimulate those wishes at the basis of dreams that, again due to the development of these functions, have been removed and now return in the form of unconscious wishes in the dreams. Thus, in young children who have not yet developed superego functions, dreams are mostly free from distortion (which is unnecessary) ${ }^{2}$.

From the perspective of the ontogenesis of the dreaming function, infantile dreams represent the early form of dreams and differ from typical adult dreams that show bizarre and symbolical contents, apparently with no presence of wish-fulfilment (Colace, 2003; 2010; 2013; in preparation).

For this reason, the infantile dreams of patients with frontal deficits may been-interpreted as the result of the dysfunction of certain executive functions involved in ego and superego activities (e.g., executive tasks of the ego, adaptation to reality, self-regulation of emotional and social behaviour, inhibition) that may have determined a lower ability of these subjects to waive or forbear from the fulfilment of their everyday unrepressed wishes, and a return to the most "primordial" mode of dreaming (Blake, 2014, Colace, Salotti, \& Ferreira, 2015).

This study represents an attempt to replicate the presence of infantile dreams in patients with frontal deficits.

\section{Method}

10 patients ( 6 females and 4 males), between 68 and 79 years of age, who, on the basis of instrumental examinations (SPET, MRI), showed frontal deficits (dorsolateral, fronto-orbital, frontomesial, frontoparietal, operculoinsular, cingulate gyrus, putamen). Clinically, many of these patients showed clinical signs compatible with frontotemporal neurodegenerative disorder, such as disinhibition, apathy, loss of empathy, deficiency in social cognition. In addition to the routine neuropsychological test battery (see table 1), patients were given a systematic interview on the "last dream they remembered to have had", paying particular attention to the description of the environment, the characters, the emotions and the general tone of the dream. The patients were also asked to evaluate the possible connections with their diurnal experiences and tell

2 On the effect of the ego and superego development on ontogenesis of dreaming, see: Freud, 1900, p. 267-268, 552-554; 1901, pp. 66-67; 1916-17, pp 143). The correlation between superego function development and dream bizarreness has found support more recently (Colace, 2010). 
whether the contents of their dream were unusual and / or strange compared to their experiences in state of wake. Each patient was given the "Comprehension" subtest of the WAIS-R, for an indirect estimation of their level of ability to adapt to reality, moral judgment, and social maturity. The dream reports were transcribed and evaluated with respect to the presence/absence of a clear wish-fulfilment and other infantile dimensions.

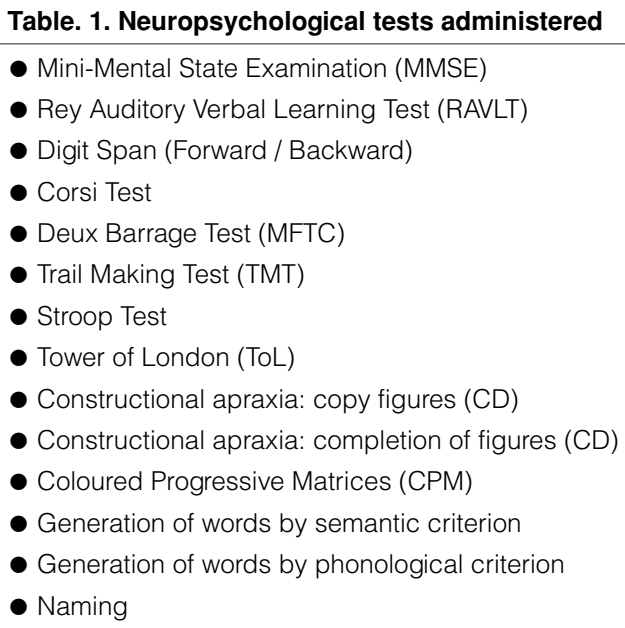

\begin{tabular}{|c|c|c|c|c|c|c|c|c|}
\hline $\begin{array}{l}\text { Patient } \\
\text { No. }\end{array}$ & $\begin{array}{c}\text { Stroop } \\
\text { Test } \\
\text { (Time) }\end{array}$ & $\begin{array}{c}\text { Stroop } \\
\text { Test } \\
\text { (Errors) }\end{array}$ & TMT (B) & TMT (B-A) & $\begin{array}{l}\text { Digit } \\
\text { Span }\end{array}$ & $\begin{array}{c}\text { Generation } \\
\text { of words by } \\
\text { phonological } \\
\text { criterion }\end{array}$ & $\begin{array}{l}\text { Generation of words by } \\
\text { semantic criterion }\end{array}$ & London Test \\
\hline 1 & 4 & 0 & 0 & 0 & 3 & 1 & 2 & 4 \\
\hline 2 & 0 & 2 & 0 & 0 & 0 & 4 & 4 & 4 \\
\hline 3 & 4 & 4 & 2 & 1 & 2 & 4 & 3 & 4 \\
\hline 4 & 0 & 0 & 0 & 0 & 3 & 2 & 0 & 0 \\
\hline 5 & 4 & 4 & 4 & 4 & 4 & 4 & 4 & 2 \\
\hline 6 & 0 & 3 & 1 & 4 & 2 & 3 & 2 & 2 \\
\hline 7 & 0 & 0 & 0 & 0 & 2 & 2 & 1 & 1 \\
\hline 8 & 0 & 4 & 2 & 3 & 4 & 4 & 4 & 4 \\
\hline 9 & 1 & 1 & 4 & 4 & 4 & 4 & 4 & 4 \\
\hline 10 & 0 & 3 & 2 & 3 & 2 & 4 & 4 & 4 \\
\hline
\end{tabular}

\section{Results}

\section{Typical Neuropsychological Profile}

At the neuropsychological level, the typical profile of the patients examined is represented by a subject oriented in space and time, with general cognitive functions near normal limits, good reasoning and language skills, memory within the norm. The typical patient shows deficits in executive functions, in particular in the ability to inhibit the non-relevant automatic response and the attentional shifting (see weighted scores in table 2).

\section{WAIS-R Comprehension subtest}

These patients reported low raw scores in the Comprehension subtest (WAIS-R),especially in items more closely related to problematic situations in which the subject must respond using social and moral judgment (e.g., item No. 2 "What should be done if one finds a sealed envelope on the street, with the stamp not stamped and with the address? ", No. 4" Why are laws necessary to protect child labour? “, No. 11, "Why is a doctor's prescription needed to buy certain drugs? “). In particular, these 


\begin{tabular}{|c|c|c|c|}
\hline Patient No. & Raw Scores & $\begin{array}{l}\text { Weighted } \\
\text { Scores }\end{array}$ & $\begin{array}{c}\text { Sum of raw scores obtained in "moral items" } \\
\text { by patients (max obtainable: } 14 \text { ) }\end{array}$ \\
\hline 1 & 8 & 4 & $4^{a}$ \\
\hline 2 & 19 & 9 & 6 \\
\hline 3 & 11 & 5 & 4 \\
\hline 4 & 19 & 9 & 7 \\
\hline 5 & 20 & 10 & 9 \\
\hline 6 & 6 & 3 & 1 \\
\hline 7 & 3 & 1 & 0 \\
\hline 8 & 21 & 11 & 9 \\
\hline 9 & 30 & 17 & 13 \\
\hline 10 & 19 & 9 & 8 \\
\hline Average & 15.5 & $\begin{array}{l}7.8 \\
\text { (average in normal } \\
\text { subjects: } 10^{1}\end{array}$ & $6.1^{2}$ \\
\hline
\end{tabular}

patients, in the sum of the raw scores obtained in the "moral" items ( $\left.{ }^{\circ} 2,4,6,7,8,11,16\right)$, had an average of 6.1 points (the maximum obtainable is 14) (see complete scores in table 3 ).

${ }^{1}$ In weighted scores, patients are slightly below the average of normal population.

${ }^{2}$ Patients show a greater deviation from normality in the average score of the sum of scores obtained in the "moral items" ( $\left.{ }^{\circ} 2,4,6,7,8,11,16\right)$.

a The scores in patients who reported infantile dreams (in bold, in grey cells) are lower (average) than those of the patients who reported other types of dreams (in italics) (5.8vs 9).

\section{Types of dream reports}

Of the 10 patients examined, 5 reported "infantile" dream reports, 2 anxiety dreams with awakening, 2 did not remember any dreams, 1 reported a typically bizarre dream. The infantile dreams of these patients were characterized by the presence of the direct fulfilment of a strong (conscious) wish of the patient. These dreams were rather short and lacked the complexity and bizarreness that habitually hinder the understanding of the meaning of adult dreams. They were dreams with a clear meaning with respect to the dreamer's waking experiences. A few examples are reported below ${ }^{3}$ :

Patient A: "I dreamed of the bottom of the sea, swimming above and below the seabed, beautiful to look at. There was the joy of being at the bottom of the sea, I was happy ... I did somersaults ... It was a very beautiful dream ".

In reality, the patient swims only on the surface of water, because he is afraid of deep waters.

Patient B: "We were walking around casually, and there were also some friends of mine and my

3 The "infantile" dreams reported by our patients refer directly to the realization of conscious wishes that cannot come true in their state of wake (e.g., the patient who still dreams of doing his beloved job). From this point of view, these wish-fulfilment dreams resemble "compensation dreams" in preschool children, i.e. dreams that derive from a clearly negative affective state or experience, such as, for example, the loss of a loved one - that person is still alive in the dream - or some other negative situation. The wish that is represented as satisfied in the dream consists of the occurrence of the opposite of what happened in daytime (i.e., the negative situation) (Colace, 2010, 2013; Mari, Beretta \& Colace, 2018). 
mother too. My sister was not there. My mother was there. We were in the garden of the house ". The patient in the dream is with the mother (who died in reality).

Patient C: "We were on duty (at work), we had to do an intervention in the woods and there were jobs that were not okay, that had not been done properly and so we took action according to the law. In the dream there were the work colleagues and the citizens who had acted against the law. My feelings were about discipline, rules, things that should not be done. The dream was pleasant, because it was about things I had always done in my life. ".

In the dream, the patient recalls his beloved work that he no longer does.

\section{Discussion}

The indications of this study are in line with previous observations on the presence of an "infantile" mode of dreaming in adult patients with a frontal deficit (Frank, 1950; Blake, 2014; Colace, Salotti, \& Ferreira, 2015). For example, in the study by Blake (2014), a patient with Urbach-Wiethe syndrome, with damage to the amygdala, reported the following dream, that overlaps completely to the findings of our work: "I dreamt that my deceased pet dog was alive again, and I hugged him.” (Blake, 2015, p.92).

The presence of these dreams in our patients represents the return to an ontogenetically earlier mode of dreaming, normally present in preschool children due to incomplete ego and superego functions development. Indeed, dreams of our patients are very similar to young children's dreams, that is, they are clear and brief, and refer to the direct accomplishment of a wish unfulfilled in daytime.

The brain areas where our patients show deficits (dorsolateral, fronto-orbital, frontomesial, frontoparietal, operculoinsular, cingulate gyrus, putamen) play an important role in executive functions (e.g. Stuss \& Levine, 2002; Bechara, Damasio, Damasio, 2000; Damasio, 1994; Myers Swett, \& Miller, 1973; Schore, 1996; Raine \& Yang 2006; Horn, Dolan, Elliott, Deakina, \& Woodruff, 2003, for review: Yu 2003), some of which are exactly involved in ego and superego activities. In this perspective, the presence of "infantile" dreams in our patients might be interpreted as the negative result that their executive functions deficits have on some aspects related to the area of impulse inhibition, regulation of emotional behaviour and cognitive flexibility, that could serve the more general ego and superego psychic function. In particular, in our patients, this altered functioning of the ego and the superego might have changed their ability to waive or forbear from the fulfilment of unrepressed wishes of everyday life, now able of acting (unlike from what happens in healty adults)) as strong wishful impulse that triggers the dreams, as it occurs in young children (i.e., a sort of "infatilisation" of psychic functioning).

Our interpretation is in line with Blake's conclusion that the presence of infantile dreams observed in patients with (UWD) Urbach-Wiethe syndrome (i.e, congenital damage to the amygdala) would suggest that the basolateral amygdala may be involved in the superego circuits that govern the pervasive unpleasant distortions and complications found in the dreams of normal adults (Blake, 2014). Furthermore, Blake suggests that "...if the dreams of UWD patients are similar to those of young children, then this raises the interesting idea that the basolateral amygdala could play a role in the circuits that underlie superego functions in the human brain" (p.66).

The presence of anxiety dream reports also confirmed observations in previous clinical case study (Colace, Salotti, \& Ferreira, 2015). Their presence would be interpreted as the result of a more frequent failure (complete or partial) of dream-censorship activity in the inhibition and disguise of inadmissible latent contents potentially threatening to the dreamer's ego.

On the other hand, it must be said that we did not find in our patients dreams with a clear expressly repressed unconscious material. From this point of view, we must consider that these patients, although showing a hypofunctioning of some ego and superego functions, maintained a certain degree of operativeness of these psychic instances. In particular, we hypothesize that the repressing functions of the superego, although with less demanding standards, are still operational and active. This latter situation would prevent the more morally and ethically rep- 
rehensible unconscious material from emerging directly 4 .

The fact that we have considered both infantile and anxiety dreams as a favourable case for the Freudian dream theory could lead us to consider the predictions of this theory as somewhat ambiguous. It is not so. Based on this theory, if we had found that the majority of these patients, despite the deficits in their ego and superego functions, continue to report typically bizarre dreams and/or dreams apparently with no wish fulfilment, as it happens in healthy adults, this would had been an unambiguous case, contrary to the theory.

The small number of patients examined does not allow a meaningful analysis of the differences with respect to any brain structure deficit and any particular pattern between those who dreamt in infantile way and the rest. However, at descriptive level, it can be noticed that four out of five patients who reported infantile dreams showed frontal deficits, in particular in the dorsolateral, frontomesial, frontoparietal, fronto-orbital or frontoparietal portions, while of the three patients reporting non-infantile dreams, two showed damage at operculoinsular and cingulate gyrus level and in the parietal and temporal lobes of the brain.

The patients who reported infantile dreams reported a lower average score in "moral items" (Comprehension subtest) than the three patients who reported anxiety dreams with awakening and bizarre dreams (see table 3). This latter result is in line with our interpretation that the patients who dreamed in an "infantile" way would seem to show more negative consequences in the ego and superego functions.

The findings of this study are based on the analysis of the transcriptions of the dream reports and, from a methodological point of view, they represent an improvement of the previous clinical case based on interviews about the changes in the dreaming that occurred in patients after the onset of frontal deficits. However, the reliability of our results could be further supported by additional research and by the use of control groups composed of healthy subjects and patients with deficits in other brain areas.

\section{References}

Blake, I., The role of the amygdala in dreaming. Master Dissertation, University of Cape Town. South Africa, 2014.

Bechara, A., Damasio, H., \& Damasio, A.R. (2000). Emotion, decision making and the orbitofrontal cortex. Cerebral Cortex, 10,295-307.

Boag, S. (2017). On dream and motivation: comparison of Freud's and Hobson's view. Front Psychol., 7:2001. doi: 10.3389/ fpsyg.2016.02001

Boag, S. (2017). Metapsychology and the foundations of psychoanalysis. Attachment, Neuropsychoanalysis and Integration. London \& New York: Routledge.

Colace, C. (2003). Dream bizarreness reconsidered. Sleep and Hypnosis, 5(3), 105-128.

Colace C. (2010). Children's dreams: From Freud's observations to modern dream research. London: Karnac Books Ltd: 2010.

Colace, C. (2013). Are wish-fulfilment dreams of children the royal road for looking at the functions of dreams? Neuropsychoanalysis, 15(2), 161-175.
Colace C. (in preparation). Early forms of dreaming: A longitudinal single-case study on the dream reports of child from the age of 4 to age of 7.

Colace, C., Salotti, P., \& Ferreira, M. (2015). Reduction of dream bizarreness in impaired frontal cortex activity: a case report. Sleep and Hypnosis, 17(1-2), 14-18.

Damasio, A.R. (1994). Descartes' error: emotion, reason, and the human brain. New York: Grosset/Putnam.

Doricchi, F., Violani, C. (1992). Dream recall in brain-damaged patients: a contribution to the neuropsychology of dreaming through a review of the literature. In J. S Antrobus \& M. Bertini (Eds.), The Neuropsychology of Sleep and Dreaming, (pp. 99-129). Hillsdale, NJ: Lawrence Erlbaum Associates, Inc.

Frank, J. (1950). Some aspects of lobotomy (prefrontal leucotomy) under psychoanalytic scrutiny. Psychiatry, 13, 35-42.

Freud, S. (1900). The Interpretation of Dreams. In J. Strachey (Ed.), The complete psychological works of Sigmund Freud, (vol. 4-5). London: Hogarth Press.

4 On the theoretical issues about dream censorship, repression and anxiety dreams see the important contribute by Simon Boag (2016, 2017). 
Freud, S. (1916-17). Introductory Lectures on Psycho-Analysis. In J. Strachey (Ed.), The complete psychological works of Sigmund Freud, (vol. 15-17). London: Hogarth Press.

Freud, S. On dreams. (1901). The Standard Edition. New York- London: W.W. Norton \& Company.

Horn, N.R., Dolan, M., Elliott, R., Deakin J.F.W., \& Woodruff PWR. (2003). Response inhibition and impulsivity: an fMRI study. Neuropsychology, 41, 1959-1966.

Mari, E., Beretta, M., Colace, C. (2018). L'appagamento di desiderio e il ristabilimento affettivo nel sogno infantile: nuove osservazioni. Psychofenia, 37-38: 15-26.

Myers R.E., Swett, C.S., Miller, M. (1973). Loss of social group affinity following prefrontal lesions in free-ranging macaques. Brain Research, 64:257-269.

Raine, A., \& Yang, Y. (2006). Neural foundations to moral reasoning and antisocial behavior. Scan, 1, 203-213.

Schore, A. (1996). The experience-dependent maturation of regulatory system in the orbital prefrontal cortex and the origin of development psychopathology. Development and Psychopathol- ogy, 8,59-87.

Solms, M. (2000). Dreaming and REM sleep are controlled by different brain mechanisms. Behavioral and Brain Sciences, 23, $843-850$.

Solms, M. (1997). The Neuropsychology of Dreams: A Clinico-Anatomical Study. Mahwah, NJ: Lawrence Erlbaum Associates Publishers.

Solms, M., \& Turnbull, O. (2002). The brain and the inner world: an introduction to the neuroscience of subjective experience. New York: Other Press.

Stuss, D.T., (2002). Levine B. Adult clinical neuropsychology: lessons from studies of the frontal lobes. Annual Review of Psychology, 53,401-433.

$\mathrm{Yu}$, C.K.-C. (2003). Neuroanatomical correlates of dreaming, III: The frontal lobe controversy (dream censorship). Neuro-psychoanalysis, 5:159-169.

Yu, C. K.-C., (2007). Cessation of dreaming and ventromesial frontal region infarcts. Neuro-Psychoanalysis, 9: 83-90. 